\title{
Kaplan-Meier And Cox Regression Analyses of Exclusive Breastfeeding Discontinuation In Mansoura, Egypt
}

\author{
${ }^{1}$ Abdel-Hady El-Gilany, ${ }^{2}$ Dina Abdel-Hady, ${ }^{1}$ Doaa M. Abdel-Hady \\ ${ }^{1}$ Public Health Department, ${ }^{2}$ Genetic Unit, Pediatric Department, Faculty of Medicine, Mansoura \\ University, Egypt. \\ Submission Date: 14-03-2021 Revision Date: 11-04-2021 Acceptance Date: 11-04-2021
}

\begin{abstract}
Background: Exclusive breastfeeding $(\mathrm{EBF})$ is the single most cost-effective intervention to reduce infant mortality in developing countries. However, most studies concluded that a large proportion of infants are not exclusively breastfed. Objectives: to estimate duration of EBF using Kaplan-Meier analysis and to find out the independent factors associated with early cessation of EBF. Method: A cross-sectional descriptive study was carried out on 884 motherinfant pairs during vaccination at age of six months in Mansoura District, Egypt. Data collected are: sociodemographic characteristics of mothers, infants their families, antenatal, natal and postnatal data. Kaplan Meier estimator were used to produce valid estimates of EBF duration and the Cox's proportional hazards model was fitted to identify risks of early EBF discontinuation. Results: At six months $14.8 \%$ of infants are still exclusively breastfed. The median period of EBF was 4.0 months. The independent risk factors of EBF discontinuation are maternal work (Adjusted Hazard Ratio $(\mathrm{AHR})=1.6$, Confidence Interval $(\mathrm{CI})=1.3-1.9)$, preterm births $\mathrm{AHR}=1.4, \mathrm{CI}=1.1-1.1)$, urban residence $(\mathrm{AHR}=1.3, \mathrm{CI}=1.1-1.5)$ and being female infant ( $\mathrm{AHR}=1.2, \mathrm{CI}=1.1-1.4)$. Conclusion: The median duration of EBF is below the recommended; and early discontinuation was associated with many factors that should be considered in designing breast feeding promotion programs.
\end{abstract}

Keywords: Kaplan-Meier - Cox regression - exclusive breastfeeding-early discontinuation

Correspondence: Doaa M. Abdel-Hady Email: doaahady2000@gmail.co

\section{Introduction}

Exclusive breastfeeding (EBF) is defined as infant feeding on human milk without any supplements of any type except for minerals, vitamins, and medications, with no other fluids or food even juices and plain water. ${ }^{1}$ The benefits of exclusive breastfeeding are well documented and infants who are on exclusive breastfeeding for the first six months have a lower probability for respiratory diseases, gastrointestinal fections, low linear growth rates and cognitive impairment. ${ }^{2}$ In Egypt, EBF is a frequent practice but not general. Among infants below the age of 2 months, $79 \%$ were counted to be exclusively breastfed. However, this proportion decreases dramatically among older infants by the age between 4 and 5 months. Supplementary foods or drinks are reported in around 7 in 10 babies, with somewhat more than 3 in 10 given complementary foods. ${ }^{3}$

Existing information on EBF in Egypt has been largely derived from cross sectional studies to measure EBF rate at specific age e.g. 4 months, 6 months with little attention to the variability in its duration and high 
chance of maternal recall bias. Owed to the benefits of EBF, knowledge about its epidemiology and factors that hinder or facilitate its practice need periodical update in the context of health and planning of public policies. the present analyses using Kaplan Meier estimator which adjusted the under calculated duration of breastfeeding used to be calculated by traditional methodology, intend to provide information about the duration of EBF and to find out the independent factors associated with early cessation of EBF.

\section{Method}

This is a cross-sectional study conducted in Mansoura, Egypt between January $1^{\text {st }}$ and March 31, 2019.

All apparently healthy infants aged six months and their mothers.

Twins and infants who had specific feeding problems (e.g. cleft lip and palate) were excluded.

Data were collected from mothers through interview during vaccination sessions at primary health care (PHC) facilities.

Sample size was calculated using MedCalc Statistical Software version 14.8.1 (MedCalc software bvba, Ostend, Belgium). A previous study in the same locality found that 13.6 of infants were exclusively breastfed at the age of six months. ${ }^{5}$ With 0.05 alpha error, $80 \%$ study power and $3 \%$ precision, the sample size needed was calculated to be at least 884 .

According to the local Health Directorate statistics, the total live births in 2018 were 27378 distributed as $60 \%$ in rural and $40 \%$ in urban areas. All PHC facilities (11 health offices in urban areas and 39 family health centers/ rural health units in rural areas) were included in the study. Sample was disseminated using birth registry at PHC facilities proportionally. All the mothers and infant dyad visiting vaccination clinic were enrolled in the study. The studied mother and infant dyad was recruited sequentially till the needed sample size was fulfilled. During the vaccination sessions, mothers were interviewed by nurses who completed data collection sheets.

Mothers completed an Arabic questionnaire covering the socio-demographic data about the mother and family, as well as type and place of birth. Infant's sex, weight at birth, birth order, gestational age, previous hospitalization, pre-lacteal feeding and time of first suckling were recorded. The family socioeconomic level was estimated using El-Gilany et al, 2012. ${ }^{4}$ Information about current feeding was collected by asking about breastfeeding and any other liquids or food ingested in the previous 24 hours.

The outcome variable or event of interest is 'end of EBF' i.e. at the point of introduction of complementary food and when breastfeeding becomes partial if continues. "Exclusive breastfeeding" is defined as the consumption of breast milk without any additional semisolid/ semisolid foods or liquids; intakes of oral rehydration solution (ORS), syrups or drops of minerals, vitamins or medications. ${ }^{1}$ If mother was not EBF to her infant, the age of start of complementary food was recorded in complete months.

\section{Data analysis}

Data were analyzed using SPSS version 23. The duration of EBF was created considering the month in which EBF was stopped. Cessation of EBF was measured as the event of interest. Those who continue to breastfeed their infants exclusively after the first six months were labeled as censored observations. Presence of censored data makes the traditional statistical methodology unsuitable. The optimum statistical technique in this condition is survival analysis, which is a method of assessing time to event data in the presence of censored cases. The median durations of EBF and their 95\% CIs were derived using non-parametric Kaplan-Meier Survival 
analysis. Log-rank test was used to compare duration of EBF for risk factors.

The significant covariates in univariate analysis were included in a multivariable Cox proportional hazard model using Wald forward stepwise procedure. Adjusted hazard ratios and their 95\% CIs were calculated. $\quad \mathrm{P} \leq 0.05$ was considered statistically significant.

\section{Ethical consideration}

The research was accepted by Institutional Research Board of the Medical College, Mansoura University (code number: R.19.09.615). Informed consents to contribute in the study were collected from mothers before the interview.

\section{Results}

At the age of six months only $14.8 \%$ of infants are exclusively breastfed and the overall median duration of EBF was 4.0 months. Table 1 shows that infants from rural area are exclusively breast fed for statistically significant longer duration than infants from urban area (5 and 4months; respectively). Also, being a housewife mother increases the duration of exclusive breast feeding to 5 months compared to 4 months among working mothers. Infants belong to middle socio-economic class are breast fed for statistically significant longer duration compared to other classes.

Table 2 shows that the duration of exclusive breast feeding is statistically significant longer with male infants compared to females (5 and 4 months; respectively) and it is shorter with preterm than full term (4 and 5 months; respectively)

Table 3 reveals that the independent significant predictors of EBF are housewife mothers, full term infants, rural residence and being a male infant $(\mathrm{AHR}=1.6,1.4,1.3$ and 1.2; respectively).

Table 1: Kaplan-Meier analysis of discontinuing EBF and it variation according to the socio-demographic factors

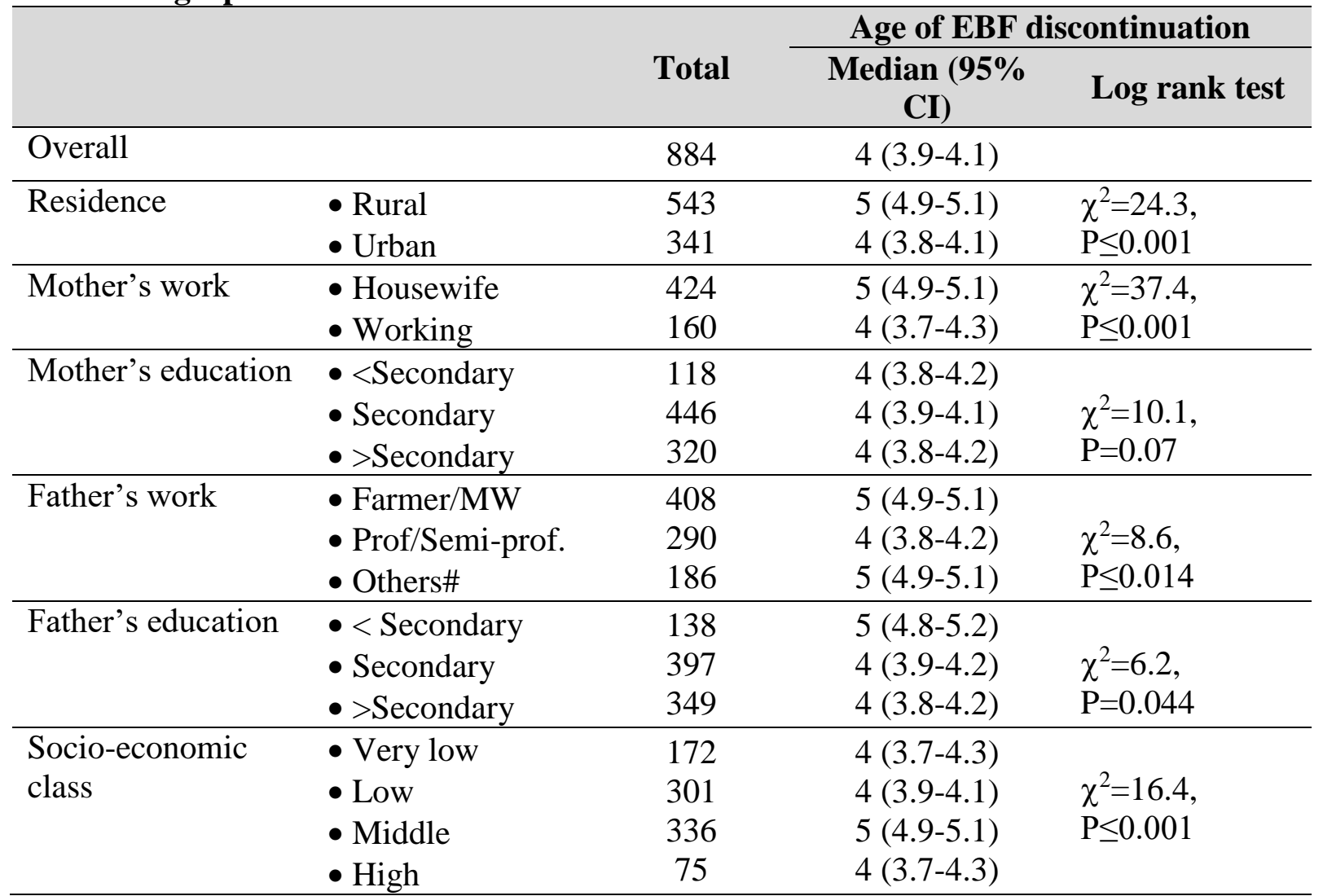


MW=Manual workers, Prof.=professional, \#others as trades, business, etc. CI=Confidence Interval Table 2: Kaplan-Meier analysis of discontinuing EBF according to the maternal characteristics and maternity care

\begin{tabular}{|c|c|c|c|c|}
\hline & & & Age of EBI & iscontinuation \\
\hline & & Total & $\begin{array}{l}\text { Median } \\
(95 \% \text { CI })\end{array}$ & Log rank test \\
\hline & $\bullet<20$ & 387 & $4(3.9-4.1)$ & \\
\hline Mother's age (years) & - $20-34$ & 422 & $4(3.8-4.2)$ & $\chi^{2}=2.8, P=0.25$ \\
\hline & - $35 \&$ more & 75 & $4(3.9-4.1)$ & \\
\hline & $\bullet<5$ & 173 & $5(4.8-5.2)$ & \\
\hline Antenatal visits & - 5-9 & 489 & $4(3.9-4.1)$ & $\chi^{2}=8.7$ \\
\hline & - 10 \& more & 222 & $4(3.8-4.2)$ & $\mathrm{P}=0.013$ \\
\hline & - Home & 83 & $5(4.9-5.1)$ & \\
\hline Place of delivery & - Governmental hospital & 242 & $4(3.8-4.2)$ & $\chi^{2}=4.1, P=0.13$ \\
\hline & - Private clinic/hospital & 559 & $4(3.9-4.1)$ & \\
\hline & - Caesarean section & 272 & $4(3.9-4.1)$ & $\chi^{2}=5.4, P=0.02$ \\
\hline Mode of delivery & - Vaginal delivery & 612 & $4(3.9-4.1)$ & \\
\hline & - First-born & 345 & $4(3.8-4.2)$ & \\
\hline Birth order & - $2 \& 3$ & 434 & $4(3.9-4.1)$ & $\chi^{2}=1.4$, \\
\hline & - 4 \& more & 105 & $4(3.7-4.3)$ & $\mathrm{P}=0.5$ \\
\hline & - Male & 463 & $5(4.9-5.1)$ & $\chi^{2}=19.3$ \\
\hline Sex & - Female & 421 & $4(3.9-4.1)$ & $\mathrm{P} \leq 0.001$ \\
\hline & $\bullet \mathrm{No}$ & 820 & $4(3.8-4.1)$ & $\chi^{2}=9.8, \mathrm{P}=0.02$ \\
\hline Low birth weight & - Yes & 64 & $4(3.4-4.6)$ & \\
\hline & - No & 767 & $5(4.9-5.1)$ & $\chi^{2}=16.4$ \\
\hline Preterm & - Yes & 117 & $4(3.6-4.4)$ & $\stackrel{n}{\mathrm{P}} \leq 0.001$ \\
\hline & • No & 822 & $4(3.9-4.1)$ & $\chi^{2}=1.5$, \\
\hline Hospitalization & - Yes & 62 & $4(3.7-4.3)$ & $\mathrm{P}=0.2$ \\
\hline & $\bullet$ No & 390 & $4(3.9-4.1)$ & $\chi^{2}=8.6$ \\
\hline Prelacteal teed & - Yes & 494 & $5(4.9-5.1)$ & 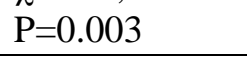 \\
\hline & - One hour or more & 532 & $4(3.9-4.1)$ & $\chi^{2}=0.1$, \\
\hline First suckling & - Within one hour & 352 & $4(3.8-4.2)$ & $\mathrm{P}=0.8$ \\
\hline
\end{tabular}

CI=Confidence Interval

Table 3: Cox regression analysis of the independent significant predictors of age of exclusive breastfeeding discontinuation

\begin{tabular}{lllll}
\hline & & \multicolumn{1}{c}{$\boldsymbol{\beta}$} & \multicolumn{1}{c}{ P } & \multicolumn{1}{c}{ AHR (95\% CI) } \\
\hline \multirow{2}{*}{ Residence } & $\bullet$ Rural & - & & $1.3(1.1-1.5)$ \\
& $\bullet$ Urban & 0.2 & 0.001 & $1(\mathrm{r})$ \\
\hline \multirow{2}{*}{ Mother's work } & $\bullet$ Housewife & - & & $1.6(1.3-1.9)$ \\
& $\bullet$ Working & 0.5 & $\leq 0.001$ & $1(\mathrm{r})$ \\
\hline \multirow{2}{*}{ Sex } & $\bullet$ Male & - & & $1.2(1.1-1.4)$ \\
& $\bullet$ Female & 0.2 & 0.004 & $1(\mathrm{r})$ \\
\hline \multirow{2}{*}{ Preterm } & $\bullet$ No & - & & $1.4(1.1-1.7)$ \\
& $\bullet$ Yes & 0.3 & 0.004 & $1(\mathrm{r})$ \\
\hline
\end{tabular}




\section{Discussion:}

In the present study, data on 884 women were analyzed, asking about breastfeeding and any other liquids or foods intake by the infant in the previous 24 hours. The overall median duration of EBF was 4 (3.9-4.1) months, this figure is much higher than the reported median duration for which children are exclusively breastfed from national Egyptian survey in 2008 which was only 2.6 months. $^{3}$

However, study finding was more consistent with studies from Sri Lanka ${ }^{6}$ and Bangladesh $^{7}$ which found 4 and 3.67 months respectively of EBF. The data from Indian National Family Health Survey, $2006^{8}$ and a Brazilian study 9 show much lower median interval of EBF as 2 months and 1 month correspondingly. On the other hand, some studies reported longer median durations. For example, a study conducted in Ethiopia, found the median duration to be 5 month $^{10}$ and in another Indian study ${ }^{11}$ it was 6 months. In Egypt EBF is communal but not prolonged enough; In general, about $65 \%$ of the mothers in Egypt feed their infants exclusively $^{12}$ and while most of infants below 2 months of age are exclusively on breast milk, the proportion drops off sharply in older infants at the age between 4 to 5 months. For example, EBF were reported as $97.5 \%, 69.3 \%$, and $13.6 \%$ at 2,4 , and 6 months; respectively using the 24-hour recall method. ${ }^{5}$

This study aimed to show the factors related to timing of cessation of EBF. Among sociodemographic factors studied, the median duration of $\mathrm{EBF}$ was longer in rural compared to urban. Moreover, rural residence increased the likelihood of prolonged EBF by 1.3 times than urban residence. Although a previous Egyptian cross section study conducted within the same locality didn't acknowledge residence as a significant factor for discontinuation of $\mathrm{EBF},{ }^{5}$ this outcome is consistent with a study conducted in Ethiopia where infants to rural mothers were EBF for 6.36 months compared to 5.13 months in urban infants. ${ }^{13}$ This is also in agreement with the findings of earlier studies reported from different countries like Bangladesh, Lebanon and Malaysia. ${ }^{14-16}$

In general, housewives tend to continue EBF for longer duration than working mothers. Previous Egyptian studies reported rates of EBF among working mothers at 6 months as low as $14.1 \%^{17}$ to $23.2 \%{ }^{18}$ and $36 \% .^{5}$ This is in consistent with two Ethiopian studies. ${ }^{13,19}$ This negative link between short maternal leaves and $\mathrm{BF}$ duration has been stated in many researches especially from developed countries like France and Belgium. ${ }^{20,21}$ This finding can be related to the fact that employed mothers are usually burdened with work and domestic duties so may have inadequate time to nurse their infants. ${ }^{22}$ In fact, mother work status in this study was found as the strongest independent predictor for the duration of EBF as working mothers had 1.6 times higher chance for earlier cessation of EBF. This was in agreement with many studies. ${ }^{22-24}$ The impact of working is less when compared to the fact denoting that working females had 3.5 times higher probability of early cessation of EBF in comparison to non-working mothers. ${ }^{19}$

The present study detected significant increase in the duration of EBF with male infants as well as full term infants with adjusted hazard ration 1.4 and 1.2 times respectively. However, in the national Egyptian survey conducted in $2008^{3}$ males were breastfed slightly longer on average than females. But this was in contrast to previous two study conducted within the 
same locality where there was no statistically significant association sex of the infant or being preterm with rates of EBF. ${ }^{5,17}$ Moreover, a European study examined those variables and found no statistically significant difference between groups. ${ }^{21}$ However, the limited effect of prematurity on the duration of EBF was confirmed in another study. ${ }^{25}$

This study, as many others, suggests that mothers from lower socioeconomic classes tend to stop EBF earlier. ${ }^{21,26}$ It was established that socioeconomic level have good influence on decision related to $\mathrm{EBF}^{27}$ It is assumed that mothers with superior socio-economic status value the advantages of breastfeeding. This may be explained by the access to information about the benefits of breastfeeding and the planning to address occasional challenges related to breastfeeding.

\section{Conclusion}

The median duration of EBF is below the recommended one and early discontinuation was associated with maternal work, preterm births, urban residence and female infants. It is important to strengthen the ongoing educational activities in health facilities and mass media and maternity leave should be compatible with the optimum duration of $\mathrm{EBF}$

Study limitations: this is a small-scale study, in one region of Egypt, and its finding cannot be generalized to all over Egypt. Moreover, the possibility of recall bias in age of introduction of complementary food cannot be excluded.

Disclosure of interest: There are no conflicts of interest either personal or financial

\section{References}

1. World Health Organization. Indicators for Assessing Infant and Young Child Feeding Practices. Washington DC, USA: WHO, 2008.
2. Victora CG, Bahl R, AJD B, GVA F, Horton $\mathrm{S}$, Krasevec J, et al. Breastfeeding in the 21st century: epidemiology, mechanisms, and lifelong effect. The Lancet 2016;387:475-90

3. El-Zanaty F and Way A: Feeding Practices and Micronutrient Supplementation. In: Egypt Demographic and Health Survey 2008. Cairo, Egypt: Ministry of Health, El-Zanaty and Associates, and Macro International, 2009

4. El-Gilany A, El-Wehady A, El-Wasify M. Updating and validation of the socioeconomic status scale for health research in Egypt. East Mediterr Health J 2012; 18: 962-8

5. Abdel-Hady DM, El-Gilany AH. Calculating exclusive breastfeeding rates: comparing dietary '24-hour recall' with recall 'since birth' methods. Breastfeed Med 2016; 11: 514-8

6. Agampodi SB, Agampodi TC, Piyaseeli UKD. Breastfeeding practices in a public health field practice area in Sri Lanka: a survival analysis. Int Breastfeed J. 2007; 2:13.

7. Giashuddin MS, Kabir M. Duration of breastfeeding in Bangladesh. Indian J Med Res 2004; 119: 267-272

8. International Institute for Population Sciences (IIPS) and Macro International. National Family Health Survey (NFHS-3), 2005-06: India: Volume I. IIPS, 2007

9. Caldeira AP and Goulart EM. Breastfeeding in Montes Claros, Minas Gerais: a representative sample study. J Pediatr 2000; 76(1):65-72

10. Woldie1 TG, Kassa AW, M. Assessment of exclusive breast feeding practice and associated factors in Mecha district, North West Ethiopia. SJPH 2014; 2(4): 330-336

11. Chudasama RK, Patel PC, Kavishwar AB. Determinants of Exclusive Breastfeeding in South Gujarat Region of India. J Clin Med Res 2009;1(2):102-108

12. Elsayed HMN, Al-Dossary LA. Exclusive breastfeeding, prevalence and maternal concerns: Saudi and Egyptian mothers. J Educ Pract 2016; 7:5-11

13. Yeneabat $\mathrm{T}$, Belachew $\mathrm{T}$, Haile $\mathrm{M}$. Determinants of cessation of exclusive breastfeeding in Ankesha Guagusa Woreda, Awi Zone, Northwest Ethiopia: a cross-sectional study. BMC Pregnancy and Childbirth 2014; $14: 262$ 
14. Giashuddin MS, Kabir M: Duration of breast-feeding in Bangladesh. Indian J Med Res 2004; 119:267-272

15. Batal M, Boulghourjian C, Abdallah A, Afifi

$\mathrm{R}$ : Breast-feeding and feeding practices of infants in a developing country: a national survey in Lebanon. Public Health Nutr 2006; 9(3):313-319

16.Tan KL: Factors associated with exclusive breast-feeding among infants under six months of age in peninsular Malaysia. Int Breastfeed J. $2011 ; 6(2)$

17.Abou-ElWafaa HS and El-Gilany AH. Maternal work and exclusive breastfeeding in Mansoura, Egypt. Family Practice 2019; 568572

18.Hassan SK, Abdelwahed WY. Knowledge \& practices of exclusive breast-

19.feeding in Fayoum, Egypt. Egyp J Commun Med 2015; 33: 61-77

20.Gebriel A: Determinants of weaning practice. Ethiop J Health Dev 2000; 14(2):183189

21.Bonet M., Marchand L, Kaminski M, Fohran A, Betoko A, Charles M, Blondel B, The "EDEN Mother-Child Cohort Study Group”. Breastfeeding Duration, Social and Occupational Characteristics of Mothers in the French 'EDEN Mother-Child' Cohort. Matern Child Health J 2013;17: 714722

22. Robert E, Coppieters Y, Swennen B, Dramaix M. Breastfeeding Duration: A Survival
Analysis-Data from a Regional Immunization Survey. BioMed Research International 2014. doi.org/10.1155/2014/529790 (accessed on 10 July 2020)

23. Asemahagn MA. Determinants of exclusive breastfeeding practices among mothers in azezo district, northwest Ethiopia. Int Breastfeed J. 2016; 11:22. doi 10.1186/s13006-016-0081-x (accessed on 10 July 2020)

24.El-Gilany AH, Shady E, Helal R. Exclusive Breastfeeding in Al-Hassa Saudi Arabia. Breastfeed Med. 2011; 6:4,209-213

25.Setegn T, Belachew T, Gerbaba M, Deribe K, Deribew A, Biadgilign S. Factors associated with exclusive breastfeeding practices among mothers in Goba district, south east Ethiopia: a cross-sectional study. Int Breastfeed J. 2012; $7: 17$

26. Peters E, Wehkamp KH, Felberbaum RE, Kruger D, Linder R. Breastfeeding duration is determined by only a few factors. Eur. J. Public Health 2006; 16 (2): 162- 167

27. Thulier D and Mercer J. Variables associated with breastfeeding duration. JOGNN 2009; 38 (3): 259-268

28.Sinclair S, Huston V, Shields K, Snelling S. Breastfeeding Practices in Northern Ontario. A report from the Northern Ontario perinatal and child health survey consortium. December 2003. https://www.research

gate.net/publication/238791323 (accessed on 5 June 2020)

\section{The Egyptian Journal of Community Medicine $\quad$ Vol. $40 \quad$ No. $1 \quad$ January $\quad 2022$}

